\title{
A Survey of Information Seeking-Behavior of Academic Staff in a Nigerian University in Digital Age
}

\author{
Blessing Esuru Ahiauzu', Okon Edet Ani ${ }^{2}$, * \\ ${ }^{1}$ University Library, Rivers State University of Science and Technology, Port Harcourt, Nigeria \\ ${ }^{2}$ Library Department, University of Calabar, Calabar, Nigeria
}

Email address:

blessahiauzu@yahoo.com (B. E. Ahiauzu), ahiauzu.blessing@ust.edu.ng (B. E. Ahiauzu), anioedet@yahoo.com (O. E. Ani), okon_ani@unical.edu.ng (O.E.Ani)

\section{To cite this article:}

Blessing Esuru Ahiauzu, Okon Edet Ani. A Survey of Information Seeking-Behavior of Academic Staff in a Nigerian University in Digital Age. Science Journal of Education. Vol. 3, No. 4, 2015, pp. 89-94. doi: 10.11648/j.sjedu.20150304.14

\begin{abstract}
The paper surveys the patterns of information-seeking behavior of academic staff in Nigeria in the emerging electronic information environment. Academic staff in Rivers State University of Science and Technology (RSUST), Port Harcourt, Nigeria were used as respondents in the survey. Questionnaire survey was used as research method for data collection. The findings of the study have shown that, the information-seeking behavior of academic staff in RSUST is in favor of electronic information sources on the Internet, as the Internet was the most frequently used information source (31.59\%), closely followed by personal contacts/collections $23.98 \%$, workshop/conferences/seminars $(23.72 \%)$ than the traditional library (20.71\%). The paper recommends that, the librarians, university managements, the governments etc. must respond proactively to meet the changing information-seeking behavior of academic staff through effective development of electronic information sources - the Internet and virtual libraries in Nigerian universities for efficiency in research and sustainable national development.
\end{abstract}

Keywords: Information and Communication Technology, Information Sources, Internet, University Library, Nigeria

\section{Introduction}

Nigerian universities are witnessing tremendous transformations and innovations in the conduct of academic research attributable to the emergence of digital age and the information and communication technology (ICT) revolution, which have influenced different ways in which information is accessed and retrieved by the academic community. Yet despite the proliferation of computerized access, digitized information formats, and the plethora of resources on the Internet, access and retrieval capabilities of academic staff in Nigerian universities, who are traditionally accustomed to manual library systems, are open to question (Kakai, IkojaOdongo and Kigongo-Bukanya, 2004). Put differently, has there been any paradigm shift in the pattern of information seeking behavior of academic staff in Nigerian universities due to the availability and accessibility of modern digital technologies such as the Internet and the changing information formats? And what are the responses or reactions of Nigerian librarians to the challenges of meeting the information needs of their patrons in the advancing electronic information environment and globalized research community?

Recent decades have witnessed innovations in scholarly communication among research scientists on a global scale which are largely attributable to the development of electronic publishing. According to Gleeson (2001), electronic publishing - particularly on the Internet - has altered the way in which scholarly information is disseminated throughout the world. And with the advent of electronic publishing and digitization, not only has collection development in libraries been improved, but libraries are now moving from information 'holding' to information 'access' (Ellis and Oldman 2005). The transition from print to electronic format, apart from resulting in a growth of electronic information, has provided users with new tools and applications for information seeking and retrieval (Tsakonas and Papatheodorou, 2006). Globalization and digital technologies have not only affected the way information is spread but the way information is acquired and how academic staff seek the information needed for their researches.

This paper aims to explore the impact of these 
technological changes in Nigeria; specifically, how the information seeking behavior of academic staff in Nigerian universities is being affected by the advancing information revolution. The study is significant in that high quality research is important in Nigeria's quest for nation building/national development as well as meeting the millennium goals of the present government, and this cannot be realized unless the information needs of Nigerian academic staff are adequately met.

\section{Information-Seeking Behavior}

Information seeking behavior refers to the way people search for and utilize information, and is thus of particular interest to librarians who strive to develop collections, services, and organizational structures that facilitate access to information by their users. Information seeking behavior is also seen as a process in which researchers purposefully engage in order to change their state of knowledge. Thus, information seeking behavior resulted from the recognition of some needs, perceived by the users, who as a consequence make demand on formal system such as libraries and information centres to satisfy the perceived information needs (Singh and Satija, 2006). And in order to satisfy his/her information needs, the user actively undergoes the information seeking process; and the aim of information seeking is to positively increase the user's knowledge of certainty or to reduce the level of confusion faced by user with a wide variety of sources of information (Singh and Satija, 2006; Edem and Bassey, 1999). Thus in their study, Ocheibi and Buba (2003), have described information seeking behavior to include the purposes of information seeking, the means, tools, information sources, approaches and the library facilities use. An exploration of the information seeking behavior of academic staff in Nigerian universities would help academic librarians to see how better and more efficient information services could be provided to ensure optimal satisfaction of their users.

\section{Brief Literature Review}

Nobert and Lwoga (2013) explored information seeking behavior of physicians at the Muhimbili National Hospital $(\mathrm{MNH})$ in Tanzania. It was found that, in order to satisfy their information needs, physicians preferred to seek information from formal sources, which included printed sources (textbooks/journals) and electronic resources (ebooks/ejournals, electronic databases etc.). Tury, Robinson and Bawden (2015) studied information seeking behavior of distance learners at the University of London. A variety of factors were found to influence information seeking behavior of the respondents. These include ease and speed of access, familiarity of sources, and level and subject of the study. Garcia-Cosavalente, Wood and Obregon (2010) did a study that explored health information seeking behavior of urban and rural Peruvians and found differences in the ways urban and rural Peruvians obtain information about health related issues; while urban respondents have advantage of using the Internet, rural dwellers preferred use of radio. A similar study was conducted by Islam and Ahmed (2012) in which they reviewed information needs and information seeking behavior of rural dwellers. The findings of the study revealed that there are similarities between information needs and information seeking behavior of rural dwellers across different countries in the review.

Gleeson (2001) conducted a study at the National Institute of Environmental Health Sciences (NIEHS) in Britain in which she examined how the availability and accessibility of electronic journals on the Internet has affected the information seeking behavior of scientists. The main goal of study was to educate the librarians at the NIEHS Library about preferences of their patrons, in order to assist them in making appropriate decisions about the library's print and electronic collections. The study revealed that most scientists have integrated electronic journals into their information seeking routines and that access to electronic journals has "in turn affected the physical usage of the library" among the scientists surveyed.

Wessel et al. (2006) conducted a survey of clinical research coordinators at the University of Pittsburgh and the University of Pittsburgh Medical Center to solicit their perceived use and knowledge of the library's electronic resources. The study sought to understand the information searching experiences and skills of clinical research coordinators at the Medical Center. The data from this survey had indicated that clinical research coordinators would benefit from training by academic librarians at the Medical Center on how to use electronic library resources and services. Chifwepa (2003) surveyed the information searching habits in terms of the use of Intranet and Internet among the academic and research staff in the University of Zambia, The findings revealed that the University of Zambia had a well-developed network for both Intranet and Internet, and thus, available library resources could be accessed by academic staff through the Intranet. Further findings of the study had indicated that "twenty-six of the 37 of the respondents" had used the Intranet, while "thirty-five respondents indicated that they used the Internet in one way or another and only two did not use it". In terms of library, "twenty-nine of the sampled respondents used the library and majority of them indicated that they used the library regularly", and those who did not use the library indicated that they did not because there were no current materials.

In Nigeria, Edem and Bassey (1999) had studied the patterns of information seeking behavior of postgraduate students in three Nigerian universities. Their findings showed that most of the respondents used formal sources such as libraries, information centers, archives, seminars and conference proceedings, and only a few used informal sources such as colleagues, friends, lecturers and interviews to meet their information needs. Ocheibi and Buba (2003) surveyed the information needs and gathering behaviour of medical doctors and researchers in Maiduguri (including medical researchers in the University of Maiduguri Teaching 
Hospital), Nigeria. Understanding of the information needs and gathering behavior of medical researchers would help the medical librarians to acquire relevant information sources to support medical researchers in their research activities. Though, the findings of the study have shown that, most of the medical researchers used "formal information sources such as journals and books respectively", $67.1 \%$ of them did not use the library because the available information sources were reported to be outdated by the respondents. Again, only, " $9.5 \%$ of respondents reportedly use online computer network (the Internet) due to its non-availability and prohibitive cost". Ocheibi and Buba (2003) further reported that, medical researchers "who do not consult the library claimed that, they use informal sources which usually involved obtaining information from their colleagues during seminars and conferences". And a notable observation made during the study was the behavior of medical scholars during their information seeking process, where they spend a longer period of time at each visit to the library; and this is due to non-availability of electronic media such as databases both online and CD-ROM, Internet facility, etc. (Ocheibi and Buba, 2003).

Adetimirin (2004) conducted a study to gain insight into the information seeking behavior of the Catholic Religious and researchers in Dominican Institute, Ibadan, Nigeria. The findings of the survey indicated that, majority of the respondents use books to satisfy their information needs; and that, local libraries are limited in their ability to provide all the books and journals required to meet all the information needs of the Catholic religious and researchers in Nigeria due to a devaluation of the local currency. The results of the study also showed that "journals rank lower than the Internet and informal sources such as newspapers and magazines, and friends and colleagues". Adetimirin (2004) also found that, though the Internet has great potential as a source of information for research in Nigeria, "the potential is yet to be fully exploited". He reported that in order to exploit this potential, "the institute has acquired a VSAT" for effective and efficient Internet connectivity and access.

Ani and Biao (2005) had explored the impact of globalization on scientific research in Nigerian universities. The results of the study showed that ease of scientific communication, increased access to current scientific books/journals and improvements in the quality of research were considered the main effects of globalization on scientific research in Nigerian universities. These were attributed to the impact of ICTs particularly the Internet on the information seeking behavior of scientific researchers in Nigerian universities. Recently, Adeniji (2007) examined the information needs and seeking behavior of academic staff in Olabisi Onabanjo University, Ogun State, Nigeria and found that most of the respondents used the Internet first when seeking for information for their teaching and research.

Ugwu (2008) reported that, research into information seeking and use is growing significantly in a wide range of disciplines in Nigerian universities. He conducted a study that explored the information seeking behavior and information needs of social science researchers at the University of Nigeria, Nsukka. The results of the study revealed differential use of information sources by social science researchers; and that the social science researchers preferably ranked "conversation with colleagues" (i.e. personal contact) ahead of all the surveyed information sources: workshops/seminars, Internet and university libraries. This paper would examine the information sources preferably used by academic staff in both science-based and non-science based disciplines at Rivers State University of Science and Technology, Port Harcourt, Nigeria.

\section{Aims and Objectives of the Study}

The aim of the current study is to investigate patterns of information seeking behavior of academic staff in Rivers State University of Science and Technology (RSUST), PortHarcourt, Nigeria, in the context of the emerging electronic information environment and ICT revolution in librarianship and research. In specific terms, the paper would investigate the preferred information sources that are used by academic staff in RSUST in conducting their research, and make appropriate recommendations based on the findings of the survey.

\section{Research Method}

The questionnaire survey was used for data collection in the study. A random sampling technique was used in the distribution of structured questionnaires to a total of 120 academic staff in both science-based and non-science based disciplines at Rivers State University of Science and Technology (RSUST), Port-Harcourt, Nigeria. Eighty-four (84) duly completed and usable questionnaires were retrieved and used for data analysis; and this represents 70.0 percent response rate.

\section{Results and Discussion}

\subsection{Background Information of Respondents}

The respondents comprised $60(71.4 \%)$ males and 24 (28.6\%) females; $45(54.6 \%)$ of them were from sciencebased disciplines, while $39(46.4 \%)$ were from non-sciencebased disciplines. The distribution of the respondents by professional rank is shown in Table 1, with majority (32.1\%) being senior lecturers and the least responses came from assistant lecturers $(7.1 \%)$.

Table 1. Professional ranks of respondents.

\begin{tabular}{lll}
\hline Rank & No. & \% \\
\hline Professor & 9 & 10.7 \\
Reader & 21 & 25.0 \\
Senior lecturer & 21 & 25.0 \\
Lecturer (I/II) & 27 & 32.1 \\
Assistant lecturer & 6 & 7.1 \\
\hline
\end{tabular}




\subsection{Information Sources Used by Respondents}

The respondents were asked to rank the information sources they use for their research activities from 1 to 4 (with 1 and 4 as the least and highest scores respectively) by four levels of use as follows:

1 Occasionally

2 Less frequently

3 Frequently

4 Most frequently

a. The Internet

The results in Table 2 show that the Internet received the highest ranking with the score of $357(31.59 \%)$, personal contacts/collections

$271(24.0 \%)$ workshops/conferences/seminars 268 (23.71\%); while the university library had the least ranking of 234 (20.71\%). In a similar study, Adeniji (2007) had found that 50\% of his respondents had used the Internet for their research activities compared to $38 \%$ use of personal collections, $31 \%$ use of library, and $13 \%$ use of workshops/conferences/seminars respectively by academic staff in meeting their information needs in Olabisi Onabanjo University, Ogun State, Nigeria. Thus, the Internet has now become a major information resource for the conduct of research among academic staff in contemporary Nigerian universities.

Table 2. Information sources used by respondents.

\begin{tabular}{lll}
\hline Information source & Score & \% score \\
\hline Internet & 357 & 31.6 \\
Personal contacts/collections & 271 & 24.0 \\
Workshops/conferences/seminars & 268 & 23.7 \\
University library & 234 & 20.7 \\
\hline
\end{tabular}

The finding is plausible because the Internet is a reservoir of academic resources which could be accessed electronically by researchers when connected through appropriate and reliable computer networks without the limitations of time and distance. Resources on the Internet are comparatively organized and stored, retrieval is faster and efficient and less cumbersome than obtainable in the traditional library holdings. Besides, the high use of the Internet by the respondents could also be attributable to the up-to-datedness and currency of the available information resources. Due to poor funding of university libraries in Nigeria, library resources are not up-to-date, since subscriptions to these materials are irregular; these make librarians incapable of satisfying the information needs of researchers in the universities. However, through the Internet, academic staff in RSUST could have access to relevant research materials especially electronic journals that are not available in the university library, but are in other libraries or institutions within and outside the country. The Internet is therefore an essential infrastructure for resource sharing of academic materials in Nigerian universities. This formed the basis in which the National Universities Commission (NUC) in Nigeria is now subscribing to foreign electronic journals as well as digitizing the local ones and putting them online (www.nigerianvirtuallibrary.com) for ease of access by researchers in all Nigerian universities. In addition, the National Universities Commission (NUC), Electronic Information for Libraries Network (eIFL.Net) and Nigerian University Libraries Consortium (NULIB) are working collaboratively to provide electronic resources (such as EBSCO HOST, HINARI, AGORA, MEDLINE etc.) to all university libraries in order to support efficiency in research process in Nigerian universities. Thus the results of the study are in line with technological advancement, and suggest the need to develop framework for effective electronic collection development policy in Nigerian university libraries.

The findings of the survey are equally consistent with international literature. Ellis and Oldman (2005), had found in their study that "more than a half of the researchers reported using the World Wide Web and the Internet for finding information" in UK universities. Gleeson (2001) study had "revealed that majority of the scientists have integrated electronic journals (on the Internet) into their information-seeking routine and considered them an important resource". In view of the emerging trend in information seeking behavior of researchers, Azubogu and Madu (2007) had posited that "the new trend in information sourcing lies with information technology"; as the Internet has recently become the world's premier intellectual resource, hosting over a billion pages of information for academic research (Ellis and Oldman, 2005). This view is supported by Missen et al. (2009); who asserted that "with enormous resources and collaborative capacities, the Internet poses historically unique chance for African researchers" to be an integral part of the global academic and research community; "given that more academic resources are moving into the Internet - and in some cases being made available only on the Internet". Thus Ani and Ahiauzu (2008) in their study have confirmed that, within the past half decade or so the Internet has become a major information source for academic research in Nigerian universities, although most university libraries are yet to get sustainable Internet access and connectivity.

\section{b. Personal Contacts/Collections}

Personal contact/collection refers to the informationseeking behavior in which an academic researcher directly interacts with his/her peers/colleagues in an informal setting requesting for relevant information or act of collection development in which he/she acquires/subscribes to relevant books/journals (whether in print/electronic forms) for personal use. With the advent of modern information technologies, the capacity for Nigerian researchers to interact with their peers within and outside the country is enhanced through use of email and telephones. Thus, researchers can make requests for reprints/photocopying or direct subscription for relevant materials to assist them in their academic research. They can also make enquiries from their professional colleagues or experts within and outside their institutions for appropriate information to support their research. With the Internet, academic staff can download relevant ejournals/ebooks online into their laptops or print them out to build up their personal collections. 
The survey findings in Table 2 had shown that personal contact/collection was ranked as the second information source "frequently" used by the respondents for their research with a score of $271(24.0 \%)$. This underscores the significance of personal contacts/collections in research process among the respondents. Provision of enabling ICT infrastructural facilities and enhanced remuneration for academic staff can improve the level of their personal contacts/collections towards effective and efficient research process in Nigerian universities.

c. Workshops/Conferences/Seminars

In Table 2, workshop/conference/seminar was ranked as the third information source used by respondents in RSUST for research. In the digital age, regular or frequent attendance at professional workshops/conferences/seminars, nationally and internationally enhances the level of access to current research information in a given field of specialty among academic staff in Nigerian universities. Since contemporary research issues in each discipline or field of knowledge/specialization are usually discussed at workshops/conferences/seminars; each researcher has the singular privilege of obtaining first hand information on current research findings in his/her area(s) of research. Another apparent reason for the use of workshop/conference/seminar as an importance information source by the respondents may be attributable to clarification(s) made by author(s) on their research methodology, research findings, data analysis and interpretations through questions/observations/comments/contributions during the interactive sessions; which are not possible during actual reading from the journal articles. In view of the significance of workshops/conferences/seminars to support research, academic staff in RSUST and indeed all Nigerian universities should be regularly sponsored by university managements to attend relevant national/international workshops/conferences/seminars in their respective disciplines/fields of specialization for them to acquire current information to support their research activities.

\section{d. University Library}

The fundamental mission of a university library is to acquire, organize and preserve scholarly materials to staff and students of the university community for their teaching, learning and research. Hence, the university library is a primary resource for research among academic staff in RSUST. However, with inadequacy in library collections and the infiltration of newer technologies in the digital age, more researchers recently seem to rely on electronic sources than the use of the traditional library resources for their research processes (Fatoki, 2004). This may explain the reason why the respondents ranked the use of university library in Table 2 as the least information source they use for their research. It is therefore the responsibility of librarians to integrate these technologies, the Internet, computerized library services, digital libraries etc. in the provision of library services for efficiency in information access and retrieval. It is apparent that, access to electronic resources in the libraries in the emerging electronic academic environment would be a boost to the use of such libraries by academic staff. However, the current research finding is incongruent with that of Nnadozie (2006), who had found that most respondents in his survey "relied on library materials as their sources of information". These differences could be explained in terms of relative improvement in the level of awareness of the Internet as a major resource for academic research, as well as acquisition of relevant technological skills to use the Internet among researchers/scholars in Nigeria. Thus there is a need not only to provide electronic access to information in the university, but provision of adequate user education to academic staff on the use of modern technologies in the research processes and procedures in Nigerian universities.

\section{Conclusion and Recommendations}

Information and communication technology (ICT), particularly the Internet is changing the patterns of information-seeking behavior of academic communities nationally and internationally, and researchers in Nigeria are caught in this transformation. The academic staff in Rivers State University of Science and Technology have preference for the use of Internet in meeting their information seeking behavior and information needs than the use of traditional library resources. The results of the study have shown that academic staff in Nigerian universities have joined their counterparts in the developed nations to use electronic information sources, particularly, the Internet as their preferred information sources in line with the emerging information revolution. The low level of use of university library in RSUST and perhaps any other Nigerian university libraries is attributed to the fact that most library patrons (academic staff) can only access the Internet outside their university libraries, "yet many of these new technologies are meant to be maximized within information environment, of which libraries are a part" (Iwe, 2005). Nigerian university librarians must therefore respond proactively towards effective integration of the Internet, digital libraries, and other relevant ICTs in the provision of library and information services to meet users' expectations and demands in the digital age. Thus, in view of the changing information needs and information-seeking behavior of academic staff in Nigeria towards electronic resources on the Internet; and in order to meet the huge users' expectations and demands in Nigerian universities in line with trend in globalization; university managements and governments must work concertedly with the university librarians to provide effective users' satisfaction in libraries; most especially in the provision of relevant access to quality research information which is crucial in nation building. University is the bedrock for national research and development, thus, the imperative of providing the needed electronic information infrastructures in the university library, in RSUST, and indeed other Nigerian university libraries towards improved and efficient access to information for national research and sustainable development. 


\section{References}

[1] Adetimiriin, A. E. (2004). Information seeking behavior of the Catholic religious in Ibadan, Nigeria (Summary of a research note delivered at the ISIC conference, Dublin, 1-3 September) Information Research, 10(1) summary 5 Available at http://InfomationR.net/ir/10-/abs5 (accessed 24 February 2009).

[2] Adeniji, M. A. (2007). INFORMATION Needs and seeking Habits of Academic Staff in Ibogun Campus of Olabisi Onabanjo University, Osun State. Gateway Library Journal, $10(2), 127-135$.

[3] Ani, O. E., \& Ahiauzu, B. (2008). Towards Effective Development of Electronic Information Resources in Nigerian University Libraries. Library Management, 29(6/7), 504-514.

[4] Ani, O. E., \& Biao, E. P. (2005). Globalization: Its Impact on Scientific Research in Nigeria. Journal of Librarianship and Information Science, 37 (3), 153-160.

[5] Azubogu, N.C., \& Madu, C. (2007). Use of Computer and Internet Technology among the Teaching Staff of Imo State University, Owerri. H-JOLIS: Heartland Journal of Library and Information Science, 1 (2), 39-49.

[6] Chifwepa, V. (2003). The Use of the Intranet and Internet by Teaching Staff of the University of Zambia. African Journal of Library Archives and Information Science, 13(2), 119-132.

[7] Edem, U., \& Bassey, B. A. (1999). Information-Seeking Behaviour of Graduate Students in Nigerian Universities. African Journal of Education and Management, 2(2), 116-125.

[8] Ellis, D., \& Oldman, H. (2005). The English Literature Researcher in the Age of the Internet. Journal of Information Science, 31(1), 29-36.

[9] Fatoki, O. C. (2004) Impact of library Resources and the Internet on Undergraduate Students' Research: University of Ibadan. Nigeria Nigerian Libraries, 38(1), 21-33.

[10] Garcia-Cosavalente, H. B., Wood, L. E. \& Obrgon, R. (2010) Health Information seeking Behavior among Rural and Urban Peruvians: Variations in Information Resource Access and Preferences. Information Development 26 (1): 37-45.

[11] Gleeson, A. C. (2001) Information-Seeking Behaviour of Scientist and other Adaptation to Electronic Journals. Unpublished Master's Paper submitted to the Faculty of School of Information and Library Science of the University of North Carolina at Chapel Hill, North Carolina.

[12] Islam, M. S. \& Ahmed, S. M. Z. (2012) The Information Needs and Information-Seeking Behavior of Rural Dwellers: A Review. International Federation of Library Association and Institutions 38 (2): 137-147.

[13] Iwe, J. I. (2005) Globalization of Information and the Nigerian Librarian. IFLA Journal, 31 (4), 342-349.

[14] Kakai, M; Ikoja-Odongo, R; \& Kigongo-Bukanya, I. (2004) A Study of the Information-Seeking Behaviour of Undergraduate Students of Makerere University, Uganda. World Libraries 14(1).

[15] Missen, C. et al (2009) The African Universities Library Project. Available at widernet.org/proposals/AULP. htm (accessed February 25, 2009).

[16] Nnadozie, C. O. (2006) Information Needs of Lecturers in Two Private Universities in Nigeria

[17] Nigerian Library and Information Science Trend 4(1/2)44-54.

[18] Nobert, G. L. \& Lwoga, E. T. (2013) Information Seeking Behavior of Physicians in Tanzania. Information Development 29 (2): 172-182.

[19] Ocheibi, J.A., \& Buba, A. (2003). Information Need and Information Gathering Behaviour of Medical Doctors in Maiduguri, Nigeria. Journal of Education Media and Library Science, 40(4), 417-427.http:// research.dils.tuk.edu.tw/joemls (Accessed 24 February 2009).

[20] Tsakonas, G., \& Papatheodorou, C. (2006). Analysing and Evaluating Usefulness and Usability in Electronic Information Services. Journal of Information Science, 32(5), 400-419.

[21] Tury, S., Robinson, L. \& Bawden, D. (2015). The Information Seeking Behavior of Distance Learners: A Study of the University of London International Programmes. The Journal of Academic Librarianship 41: 312-321.

[22] Ugwu, C. I. (2008) The Effect of Personal Characteristics on the Use of Information Sources by Social Researchers at University of Nigerian, Nsukka. Library Philosophy and Practice (http:/www.webpages.uidaho.edu/ moblin/ugwu.htm (Accessed 24 February 200).

[23] Wessel, C. B., Tannery, W. H., \& Espstein, B. A. 2006. Information-seeking Behaviour and Use of Information Resources by Clinical Research Coordinators. Journal of the Medical Library Association, 94(1), 48-54. 